\title{
Double Pedicle Artery Rotation Sigmoid Vaginoplasty for Vaginal Aplasia Management
}

\author{
Adeodatus Yuda Handaya ${ }^{1}$, Nurcahya Setyawan ${ }^{1}$, Nuring Pangastuti ${ }^{2}$, Marijata $^{1}$, Agus Barmawi ${ }^{1}$, \\ Imam Sofii ${ }^{1}$, Muhamad Nurhadi Rahman ${ }^{2}$, Ida Ayu Setyawati ${ }^{2}$, Hamzah Muhammad Hafiq ${ }^{1}$ \\ ${ }^{1}$ Division of Digestive Surgery, Department of Surgery, Faculty of Medicine, Public Health and Nursing, Universitas Gadjah Mada/Dr. Sardjito \\ Hospital, Yogyakarta; ${ }^{2}$ Department of Obstetrics and Gynecology, Faculty of Medicine, Public Health and Nursing, Universitas Gadjah Mada/ \\ Dr. Sardjito Hospital, Yogyakarta, Indonesia
}

Sigmoid vaginoplasty has been popular for neovagina reconstruction in vaginal aplasia. The most common surgical complication was vaginal stenosis caused by inadequate vascularization and tension because of graft length. Therefore, ischemia ensued and disrupted wound healing. The selection of double pedicle artery rotation sigmoid vaginoplasty is expected to reduce this problem. Five patients from April to December 2016 were diagnosed with vaginal aplasia; 4 had history of neovagina stenosis. These patients underwent sigmoid vaginoplasty with double pedicle artery rotation. No complications occurred during or after the procedure. Assessment postsurgery was conducted at 1 year. These results suggest that double pedicle artery rotation sigmoid vaginoplasty is a safe and acceptable technique for management of vaginal aplasia. The procedure decreased tension inside vascular pedicles as a result of maintaining abundant vascularization supply. Consequently, this procedure could avert graft necrosis, leakage, and severe stenosis. All of the patients exhibited regular menstrual cycle and satisfactory sexual activity. The outcomes were excellent with remarkable anatomical and functional results.

\section{Keywords: Gynecologic surgical procedures; Disorders of sex development; Vaginal aplasia; Rotation; Wound healing}

\section{INTRODUCTION}

Müllerian aplasia, Mayer-Rokitansky-Küster-Hauser (MRKH) syndrome, or vaginal aplasia has an incidence of 1 per 4,5005,000 females. This anomaly results in agenesis or atresia of the vagina, uterus, or both [1-3].

Vaginal aplasia, which is listed in class V4 in the ESHRE-ESGE classification, usually presents in adolescents as primary amenorrhea and cyclic abdominal pain related to hematometra with otherwise normal development of secondary sexual characteristics,

Received: August 14, 2018 - Accepted: October 30, 2018

Correspondence to: Adeodatus Yuda Handaya, M.D.

Division of Digestive Surgery, Department of Surgery, Faculty of Medicine, Public Health and Nursing, Universitas Gadjah Mada/Dr. Sardjito Hospital, Yogyakarta, Indonesia

Tel \& Fax: +62-274581333, E-mail: yudahandaya@ugm.ac.id ORCID code: https://orcid.org/0000-0003-0256-1955

\section{(c) 2020 The Korean Society of Coloproctology}

This is an open-access article distributed under the terms of the Creative Commons Attribution NonCommercial License (https://creativecommons.org/licenses/by-nc/4.0) which permits unrestricted noncommercial use, distribution, and reproduction in any medium, provided the original work is properly cited.
46XX karyotype, and normal ovarian function [2]. This condition usually occurs in conjunction with MRKH syndrome and complete androgen insensitivity syndrome. The vagina is blind ending, and the vaginal length can vary from a shallow dimple to several centimeters [4]. Vaginal reconstruction is required to enable penetrative sexual intercourse [5]. At present, there is no consensus in the literature regarding the best surgical technique to provide the best functional outcome and sexual satisfaction [1].

Vaginal dilatation therapy in the United States and United Kingdom is considered the best first-line treatment, and surgery is reserved for cases when vaginal dilation therapy fails or when a patient is ineligible for vaginal dilation due to previous perineal surgery. Several techniques to create a neovagina have been proposed. These include the nonsurgical Frank technique, which relies on serial dilation of a vaginal pouch. It is a noninvasive and inexpensive method with a high success rate of up to $90 \%$. However, difficulties such as low compliance, patient dissatisfaction, discomfort, pain, and a constant reminder of their abnormality have been reported [6].

Use of isolated bowel segment in intestinal vaginoplasty has 
been shown to provide excellent results, circumventing the need for regular dilation and providing natural lubrication. Sigmoid vaginoplasty was preferred over any bowel segment because it provides an aesthetically pleasing neovagina with a good length, natural lubrication, and obviating the need for stenting and/or dilation [7]. The purpose of this study is to introduce of Double Pedicle Rotation Graft Sigmoid Vaginoplasty technique as an alternative method to prevent tension in the graft and ensure smooth graft flow to optimize wound healing prevent severe stenosis.

\section{CASE REPORTS}

From April to November 2016, sigmoid vaginoplasty was performed in 5 patients with cervical and vaginal aplasia. This study was approved by the Institutional Review Board of the Faculty of Medicine, Universitas Gadjah Mada, Indonesia under permit approval number KE/FK/0920/EC/2018. The authors attest that full and informed consent was obtained from every patient who underwent medical treatment in our hospital. The informed consent form also declared that patient data or samples will be used for educational or research purposes.
All patient records were reviewed for surgical technique, complications, anatomical results, and functional and psychosocial acceptance of the procedure. Patients were recalled for physical examination, and they underwent personal interviews to assess their current conditions. A single surgeon, with expertise in gastrointestinal surgery, performed the procedure in all the patients. A summary of these patients including pre and postoperative measures is presented in Table 1.

\section{Surgical technique of double pedicle rotation graft sigmoid vaginoplasty}

In preparation for surgery, all patients underwent a careful physical examination and thorough endocrine, psychology, and radiologic review. Endoscopic assessment of the urethra and bladder was performed just before surgery when deemed necessary. The examination involved a psychologist before and after the procedure.

- The procedure was performed under general anesthesia.

- The patient was placed in an extended lithotomy position with the buttocks slightly elevated.

- Through a median infra umbilicus incision, the descending colon was mobilized down to and including the sigmoid colon. It

Table 1. The summary of diagnosis history of past operative treatment, current treatment, post operation complications, and outcome of the procedure in the patients included in the study

\begin{tabular}{|c|c|c|c|c|c|c|c|c|c|}
\hline $\begin{array}{l}\text { Patient } \\
\text { No. }\end{array}$ & $\begin{array}{l}\text { Age } \\
(y r)\end{array}$ & $\begin{array}{c}\text { History of past operative } \\
\text { treatment }\end{array}$ & Uterus & Diagnosis & Karyotype & $\begin{array}{l}\text { Surgical } \\
\text { procedure }\end{array}$ & Outcomes & $\begin{array}{l}\text { Postoperation } \\
\text { complication }\end{array}$ & $\begin{array}{l}\text { Management } \\
\text { of complication }\end{array}$ \\
\hline 1 & 15 & $\begin{array}{l}\text { Laparotomy and vaginal } \\
\text { catheter insertion twice in } \\
2016\end{array}$ & Present & Vaginal Aplasia & $46, X X$ & $\begin{array}{l}\text { Sigmoid } \\
\text { vaginoplasty }\end{array}$ & $\begin{array}{l}\text { Satisfactory cosmetics } \\
\text { result, regular } \\
\text { menstruation }\end{array}$ & $\begin{array}{l}\text { Mild neovaginal } \\
\text { stenosis }\end{array}$ & None \\
\hline 2 & 16 & $\begin{array}{l}\text { Vaginoplasty in } 2014 \text {, } \\
\text { hematometra drainage in } \\
2015 \text {, recanalization, } \\
\text { drainage and ureter stent } \\
\text { insertion to relieve } \\
\text { vagino-cervix obstruction } \\
\text { in } 2016\end{array}$ & Present & $\begin{array}{l}\text { Vaginal and } \\
\text { cervical } \\
\text { aplasia }\end{array}$ & $46, X X$ & $\begin{array}{l}\text { Sigmoid } \\
\text { vaginoplasty }\end{array}$ & $\begin{array}{l}\text { Satisfactory cosmetics } \\
\text { result, regular } \\
\text { menstruation }\end{array}$ & $\begin{array}{l}\text { Mild neovaginal } \\
\text { stenosis }\end{array}$ & None \\
\hline 3 & 16 & $\begin{array}{l}\text { Vaginoplasty } 4 \text { times and } \\
\text { bilateral endometriosis } \\
\text { cystectomy with adhesion } \\
\text { once since } 2013\end{array}$ & Present & $\begin{array}{l}\text { Vaginal and } \\
\text { cervical } \\
\text { aplasia }\end{array}$ & $46, X X$ & $\begin{array}{l}\text { Sigmoid } \\
\text { vaginoplasty }\end{array}$ & $\begin{array}{l}\text { Satisfactory cosmetics } \\
\text { result, regular } \\
\text { menstruation, and } \\
\text { satisfactory sexual } \\
\text { activity }^{a}\end{array}$ & $\begin{array}{l}\text { Mild neovaginal } \\
\text { stenosis }\end{array}$ & $\begin{array}{l}\text { Dilatation } \\
\text { using } \\
\text { vaginal } \\
\text { dilator }\end{array}$ \\
\hline 4 & 26 & $\begin{array}{l}\text { No previous operative } \\
\text { procedure }\end{array}$ & Absent & $\begin{array}{l}\text { Vaginal aplasia } \\
\text { and MRKH } \\
\text { syndrome }\end{array}$ & 46, XX & $\begin{array}{l}\text { Sigmoid } \\
\text { vaginoplasty }\end{array}$ & $\begin{array}{l}\text { Satisfactory cosmetics } \\
\text { result and sexual } \\
\text { activitya }^{\mathrm{a}}\end{array}$ & None & None \\
\hline 5 & 29 & $\begin{array}{l}\text { Past orchidectomy, } \\
\text { clitoroplasty, and vagino- } \\
\text { plasty in } 2014 \text {. History of } \\
\text { neovaginal closure after } \\
\text { hemorrhage control post } \\
\text { vaginoplasty }\end{array}$ & Absent & $\begin{array}{l}\text { Vaginal and } \\
\text { uterine aplasia }\end{array}$ & $46, X Y$ & $\begin{array}{l}\text { Sigmoid } \\
\text { vaginoplasty }\end{array}$ & $\begin{array}{l}\text { Satisfactory cosmetics } \\
\text { result and sexual } \\
\text { activity }^{\mathrm{a}}\end{array}$ & $\begin{array}{l}\text { Mild neovagina; } \\
\text { stenosis }\end{array}$ & $\begin{array}{l}\text { Dilatation } \\
\text { using a } \\
\text { vaginal } \\
\text { dilator }\end{array}$ \\
\hline
\end{tabular}

MRKH, Mayer-Rokitansky-Küster-Hauser.

ameasured with the Female Sexual Function Index. 
was not necessary to mobilize the splenic flexure to prevent tension in sigmoid anastomosis because the sigmoid itself was redundant. The design of the procedure is shown in Fig. 1.

- A 20 -cm segment of the sigmoid colon was isolated with preservation of a minimum of two branches of vascular pedicle from the sigmoid artery and marginal artery of Drummond (Fig. 2).

- Simultaneously, another team of gynecologists incised the hymenal region of the vulva in a cruciate fashion, and the vaginal tract was bluntly dissected between the bladder and rectum to the level of the peritoneal reflection in the cul-de-sac. The culde-sac was opened over a Hegar dilator pushed up through the perineal route.

- The sigmoid graft then was rotated $180^{\circ}$ on its vascular supply with less tension to establish blood perfusion. Blood perfusion in the isolated colon was assessed by observing its peristaltic movement, fresh red color, and the presence of blood seepage at the tip of the graft. The design of the procedure is shown in Fig. 3.

- For the sigmoid anastomosis, the distal end of the sigmoid graft was anastomosed to the uterus, and the proximal end was anastomosed to the vagina with a hand-sewn simple suture to form a single-layer anastomosis with synthetic braided 2-0 absorbable sutures (Fig. 4).

The procedure mentioned above is a major operation and is always performed via the laparotomy method. Technically, it can be conducted laparoscopically by a laparoscopic gastrointestinal and

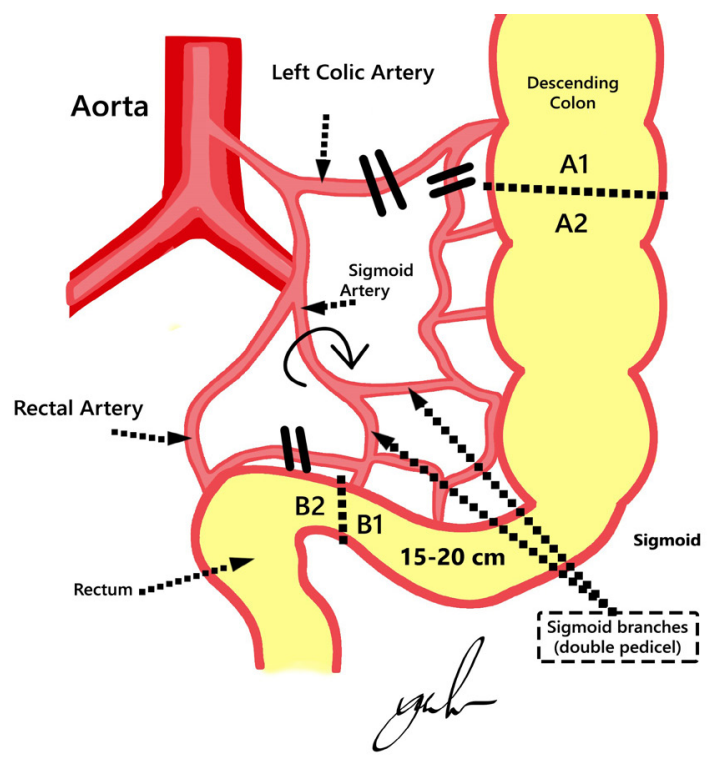

Fig. 1. Vascular pedicle preservation design. Two branches of vascular pedicles from the sigmoid artery and marginal artery of Drummond were planned to be preserved. A1-2, proximal end of sigmoid graft; B1-2, distal end of sigmoid graft; dashed line, site of incision of the isolated sigmoid segment; 2 parallel black lines, site of artery ligation. gynecological surgeon. However, our patients did not receive a laparoscopic procedure because there was no strong evidence of benefits compared with its inherent risks. Our patients then received the Enhance Recovery After Surgery Protocol for postoperative management. Enteral and parenteral nutrition programs

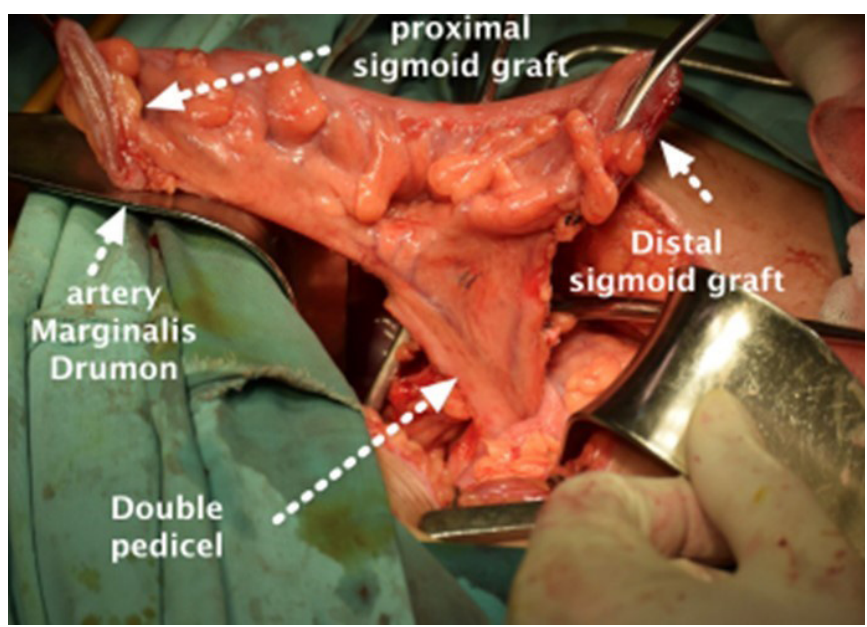

Fig. 2. Preservation of vascular pedicles. A 20 -cm sigmoid segment with its 2 pedicle branches of the sigmoid artery and marginal artery of Drummond were preserved.

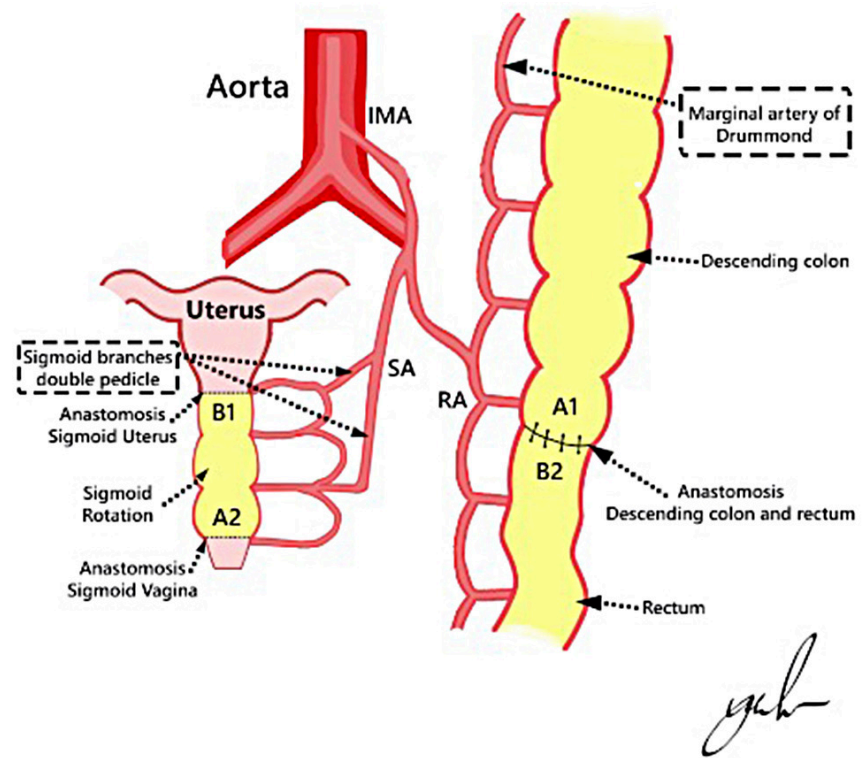

Fig. 3. Design of the procedure. The sigmoid segment then was rotated $180^{\circ}$ on its vascular supply. The distal end of the isolated colon (B1) was anastomosed to the uterus, and the proximal end (A2) was anastomosed to the vagina. IMA, inferior mesenteric artery; LCA, left colonic artery; SA, sigmoid artery; RA, rectal artery; A1-2, proximal end of sigmoid graft; B1-2, distal end of sigmoid graft; dashed line, site of incision of the isolated sigmoid segment; 2 parallel black lines, site of artery ligation. 


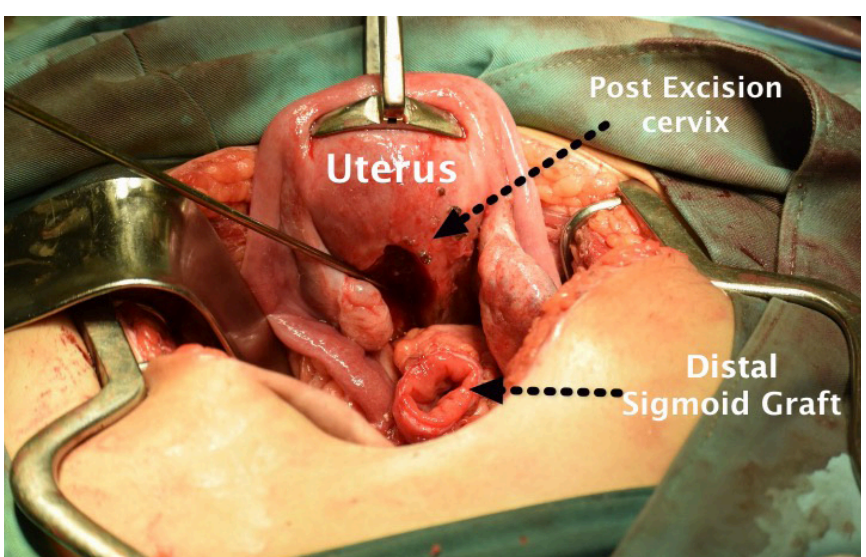

Fig. 4. Anastomosis procedure. Preparation of anastomosis procedure between the distal ends of the isolated colon (B1) with the uterus.

were started one day after surgery. The patients were also provided an injection of Ceftriaxone $1 \mathrm{~g}$ twice a day (days 1-5 after surgery) and metronidazole infusion $500 \mathrm{mg} 3$ times a day (days 1-3 after surgery). The average operative time was 3 hours, and the length of hospital stay was around 5-7 days. After discharge from the hospital, the patients took cefixime $200 \mathrm{mg}$ twice a day for 5 days.

Patients were instructed to visit the outpatient clinic regularly at $1,2,4$, and 6 weeks, 6 months, and 1 year postoperatively for evaluation. All of the patients underwent a physical examination and personal interview to assess the postoperative results, social acceptance of the procedure, and sexual satisfaction using the Female Sexual Function Index (FSFI) [8]. They were also taught self-dilation of the neovaginal introitus and irrigation of the neovagina for mucus removal and were instructed to perform the procedures daily for 8 weeks and weekly thereafter. The desired outcomes were to provide adequate passage for menstruation blood to flow in teenage patients who retained functional uterus and for sexual activity in older patients. As a result, a patient who had a uterus exhibited regular menstruation cycles with normal duration and amount of menstrual blood. Meanwhile, sexually active patients expressed excellent satisfaction in cosmetics and functional results of the procedure. None of our patients exhibited any major complication such as graft necrosis, leakage, or severe stenosis.

\section{DISCUSSION}

Vaginal aplasia, or MRKH syndrome, is a rare defect caused by embryologic underdevelopment of the Müllerian duct, originating from the failure of the sinovaginal bulbs to develop and form the vaginal plate, with resultant agenesis or atresia of the vagina, uterus, or both. The vaginal canal is markedly shortened and appears as a dimple below the urethra. A structurally normal uterus, single midline uterine remnant, or uterine rudimentary horns may be present. Approximately $7 \%$ to $10 \%$ of these women have a functional endometrium within a uterine structure. The ovaries, given their separate embryologic source, are typically normal in structure and function, though they may be found in atypical locations [1-3].

There are several classifications of female genital tract anomalies, and the most widely accepted was developed by the American Fertility Society. However, a recent classification has been published by the European Society of Human Reproduction and Embryology (ESHRE) and the European Society for Gynaecological Endoscopy (ESGE), who formulated a new classification based on an expert consensus regarding uterine, cervical, and vaginal anatomy with its variations, deviations, and anomalies. These guidelines classified uterine malformations and cervicalvaginal anomalies into seven and five classes, respectively $[9,10]$.

According to the ESHRE-ESGE classification of female genital tract anomalies, uterine anomaly class $\mathrm{U} 0$ is normal, $\mathrm{U} 1$ is dysmorphic, U2 is septate, U3 is bicorporeal, U4 is hemi-uterus, U5 is aplastic, and U6 is unclassified malformations. Cervical anomaly class $\mathrm{C} 0$ is normal cervix, $\mathrm{C} 1$ septate cervix, $\mathrm{C} 2$ is double 'normal' cervix, C3 is unilateral cervical aplasia, and C4 is cervical aplasia. Vaginal anomaly class $\mathrm{V} 0$ is normal vagina, $\mathrm{V} 1$ is longitudinal nonobstructing vaginal septum, V2 is longitudinal obstructing vaginal septum, V3 is transverse vaginal septum and/or imperforate hymen, and V4 is vaginal aplasia [10]. All of the patients in this study were diagnosed with vaginal aplasia (V4), and two of them concurrently exhibited cervical aplasia (C4). These abnormalities required neovagina reconstruction to facilitate penetrative sexual intercourse.

The ideal time for intervention is at or after adolescence when the patient has reached physical and psychological maturity. Surgical revision was almost inevitably performed in infants and prepubertal girls. The patient should be involved in treatment to increase compliance with adjuvant dilation therapy, required to prevent postoperative stenosis [5].

Surgical vaginal reconstruction could offer better outcomes when nonsurgical methods have failed. Surgical vaginoplasties can be subdivided into the following categories: (1) Creation of a perineal pouch (Williams vaginoplasty and subsequent modifications), (2) Pressure method (Vecchietti procedure), and (3) Lining a neovaginal space. These methods require long-term dilation and stenting to prevent canal stenosis and inadequacy for penetrative intercourse [6].

Intestinal vaginoplasty requires a combined perineal-abdominal approach. The procedure is major and is usually performed via laparotomy. It remains an operation with significant morbidity as it involves resection and anastomosis of the bowel [5]. Segments of the rectum, ileum, and sigmoid colon have been employed for vaginal replacement. The procedure is performed by removing a segment of bowel approximately $10-12 \mathrm{~cm}$ in length with its vascular pedicle still intact. This segment is transposed into the pelvis creating a neovagina, and the proximal end is closed. However, a 
vagina constructed from intestine will be relatively insensitive and may have excess mucus production, requiring the patient to wear pads permanently. Satisfactory sexual function outcomes from intestinal vaginoplasty have been reported, with over $80 \%$ satisfactory intercourse [11].

Vaginoplasty using the sigmoid colon is a common technique for creation of a neovagina. It is preferred over other bowel segments because it satisfies the following criteria: it is self-lubricating; mucus production is less of a problem than with the use of the small bowel; it can grow with the child when used to create a neovagina before puberty; there is a minimal risk of stenosis; it is close to the perineum; it has an easily mobilized vascular pedicle; and it does not require molds or stenting [12]. Some reports have suggested that colovaginoplasty is preferable to a split thickness skin graft or ileal conduit, because skin grafts may be associated with dyspareunia, need for constant vaginal lubrication, prolonged periods of dilatation, and less aesthetically pleasing result. The ileum tends to be more fragile, with a higher incidence of vaginal bleeding and a smaller caliber than a true vagina. The colon has the ability to sustain frictional trauma and produces a mucous discharge that acts as a natural lubricant [13]. It also does not have any tendency toward contraction, narrowing, or stenosis because the bowel segment has an adequate blood supply. Therefore, this procedure is most effectively accomplished using the sigmoid colon [14]. All of our patients were treated with the sigmoid vaginoplasty technique.

Intraoperative or intestinal complications of sigmoid vaginoplasty are rare. Postoperative complications ranged from $0.2 \%-$ $1.4 \%$ and include ileus, wound infection, pelvic hematoma, urinary tract infection, urinary incontinence, incision abscess, intestinal leakage, colorectal fistula, necrosis of the sigmoid conduit, and pelvic abscess. Long-term complications $(0.2 \%-13.9 \%)$ comprise persistent vaginal discharge, stenosis of the neovagina, prolapse of the neovagina, malodor of the vaginal secretions, and postcoital bleeding. To avoid such complications, preoperative bowel preparation and meticulous suturing are recommended [15].

Neovaginal introitus stenosis was the common complication of sigmoid vaginoplasty, usually occurring in the 2 months after the procedure. It has been confirmed that scarring or skin shrinkage rather than tension of the levator ani muscle was the main reason for this stenosis. Management of this complication varies, either using petrolatum gauze or vaginal stent; however, the core principle is to prevent the neovagina from closing and producing stricture [16].

Most patients in this study presented with mild stenosis of the neovagina. This study performed double pedicle artery rotation sigmoid vaginoplasty to reduce tension inside the vascular pedicles of the isolated sigmoid segment or graft, which supplied vascularization to the neovagina. In this technique, the sigmoid segment was rotated before placement as the neovagina. Lack of vascularization induces poor wound healing and scarring, causing stenosis of the neovagina. After a 6-month period, the outcomes of this procedure were excellent, with remarkable functional and cosmetics results and mild vaginal stenosis handled with dilation. This technique also attempted to preserve the reproductive and sexual function. The patients enrolled in this study reported that they had regular menstruation cycles with normal duration and amount of menstrual blood. Patients who were sexually active reported their satisfaction with FSFI. The sigmoid segment of the neovagina was anastomosed with the functioning uterus, allowing menstrual blood to have a course of flow and providing a path for fertilization as with a normal vagina. This construction also allowed satisfactory sexual activities.

In conclusion, double pedicle artery rotation sigmoid vaginoplasty is a safe and acceptable technique for management of women with vaginal aplasia. The critical advantage of this procedure is the decreased tension inside vascular pedicles, maintaining an abundant vascularization supply. Consequently, this procedure could avert the most common complications following reconstruction such as graft necrosis, leakage, and stenosis. The evaluation of patient menstruation cycle and sexual activity showed that this surgical approach resulted in excellent anatomi$\mathrm{cal}$ and functional outcomes.

\section{CONFLICT OF INTEREST}

No potential conflict of interest relevant to this article was reported.

\section{REFERENCES}

1. American College of Obstetricians and Gynecologists. Mullerian agenesis: diagnosis, management, and treatment. Obs Gynecol 2018;131:35-42.

2. Huguelet PS, May LT, Scott SM. An atypical presentation of vaginal agenesis. J Pediatr Adolesc Gynecol 2015;28:e123-6.

3. Motta GL, Tavares PM, Burttet LM, Berger M, Silva Neto B, Rosito TE. Vaginoplasty with full-thickness mesh skin graft for vaginal agenesis. Urology 2016;98:200-3.

4. Kimberley N, Hutson JM, Southwell BR, Grover SR. Vaginal agenesis, the hymen, and associated anomalies. J Pediatr Adolesc Gynecol 2012;25:54-8.

5. Michala L, Cutner A, Creighton SM. Surgical approaches to treating vaginal agenesis. BJOG 2007;114:1455-9.

6. Nakhal RS, Creighton SM. Management of vaginal agenesis. J Pediatr Adolesc Gynecol 2012;25:352-7.

7.Rawat J, Ahmed I, Pandey A, Khan TR, Singh S, Wakhlu A, et al. Vaginal agenesis: experience with sigmoid colon neovaginoplasty. J Indian Assoc Pediatr Surg 2010;15:19-22.

8. Rosen R, Brown C, Heiman J, Leiblum S, Meston C, Shabsigh R, et al. The female sexual function index (FSFI): a multidimension self-report instrument for the assessment of female sexual function. J Sex Marital Ther 2000;26:191-208. 
9. Bermejo C, Martínez Ten P, Cantarero R, Diaz D, Pérez Pedregosa J, Barrón E, et al. Three-dimensional ultrasound in the diagnosis of müllerian duct anomalies and concordance with magnetic resonance imaging. Ultrasound Obstet Gynecol 2010;35:593-601.

10. Grimbizis GF, Gordts S, Di Spiezio Sardo A, Brucker S, De Angelis C, Gergolet M, et al. The ESHRE/ESGE consensus on the classification of female genital tract congenital anomalies. Hum Reprod 2013;28:2032-44.

11. Davies MC, Creighton SM. Vaginoplasty. Curr Opin Urol 2007; 17:415-8.

12. Rajimwale A, Furness PD 3rd, Brant WO, Koyle MA. Vaginal construction using sigmoid colon in children and young adults. BJU Int 2004;94:115-9.
13. Webster T, Appelbaum H, Weinstein TA, Rosen N, Mitchell I, Levine JJ. Simultaneous development of ulcerative colitis in the colon and sigmoid neovagina. J Pediatr Surg 2013;48:669-72.

14. Wesley JR, Coran AG. Intestinal vaginoplasty for congenital absence of the vagina. J Pediatr Surg 1992;27:885-9.

15. Pan P. Surgical and functional outcome of sigmoid colon-vaginoplasty in Mayer-Rokitansky-Kuster-Hauser syndrome. Int J Reprod Contracept Obstet Gynecol 2017;6:4441-6.

16. Cai B, Zhang JR, Xi XW, Yan Q, Wan XP. Laparoscopically assisted sigmoid colon vaginoplasty in women with Mayer-Rokitansky-Kuster-Hauser syndrome: feasibility and short-term results. BJOG 2007;114:1486-92. 